\title{
Ultrasound-guided interfascial blocks of the trapezius muscle for cervicogenic headache: A report of two cases
}

\author{
Servikojenik baş ağrısında ultrason eşliğinde yapılan trapezius kası interfasiyal bloğu: \\ iki olgunun sunumu
}

\section{(1) Tulin ARICI}

To the Editor,

Cervicogenic headache $(\mathrm{CEH})$ is a headache arising from cervical nociceptive structures such as facet joints, disci intervertebrales, muscles, and ligaments. The structures that are innervated by the segmental nerves from $\mathrm{C} 1$ to $\mathrm{C} 3$ can be sources of $\mathrm{CEH}$. The nucleus trigeminocervicalis is formed by the pars caudalis of the spinal nucleus nervi trigemini and the gray matter from the upper three cervical spinal cord segments. The nociceptive afferents of the nervus trigeminus and the first three cervical nerves interact in this region. This interaction can result in referred pain that is felt in the sensory receptive fields of the nervus trigeminus and is a possible mechanism of $\mathrm{CEH}_{.}{ }^{[1-3]} \mathrm{CEH}$ is mostly a unilateral headache without side shift. It is typically referred pain from a source in the neck and radiates to one or more regions of the head and/or face. The most commonly affected regions are the occipital, frontal, and retro-orbital regions. It can also occur bilaterally. CEH can be provoked by cervical movements ${ }^{[4,5]}$ and be accompanied by limitations in neck movement and sometimes ipsilateral nonradicular shoulder and arm pain. ${ }^{[3,6]}$ The prevalence of $\mathrm{CEH}$ in the general population is between $0.4 \%$ and $2.5 \%$. However, in patients with headaches, the prevalence is as high as $15-20 \%$. $^{[7]}$
The CEH International Study Group (CHISG) has published diagnostic criteria for $\mathrm{CEH}$, also known as Sjaastad criteria. ${ }^{[5,8,9]}$ CHISG Diagnostic Criteria for CEH include the following: (a) Unilateral pain (although bilateral CEH may occur); (b) restriction of range of motion of the neck; (c) provocation of head pain by neck movement; (d) provocation of head pain with external pressure over the upper cervical or occipital region on the symptomatic side; (e) vague ipsilateral non-radicular or occasional radicular neck, shoulder, or arm pain; (f) confirmatory local anesthetic blocks in the cervical region; (g) marginal response to ergotamine, triptans, or indomethacin; and $(\mathrm{h})$ posterior onset of headache pain.

Myofascial trigger points (TrPs) are common factors in patients with CEH and contribute to the pain and disability. ${ }^{[10,11]}$ TrPs are painful, hyperirritable spots that localized in a taut band of skeletal muscle. They can give rise to localize or referred pain and autonomic phenomena such as vasoconstriction, pilomotor response, and hypersecretion. ${ }^{[12,13]}$ The trapezius is one of the most affected muscles. ${ }^{[14]}$

The main goal of treatment is inactivation of the TrPs, and injection techniques are a main method. The structure of the fascia can ease diffusion of an injected anesthetic during diagnostic and thera- 
peutic blocks, and interfascial injections are becoming more common. ${ }^{[14-16]}$ New knowledge about the function and anatomic content of the fascia has enhanced utilization of the interfascial block during anesthesia and pain treatment. ${ }^{[14]}$

In this report, we present two patients with CEH who had TrPs in their upper trapezius muscles. Each patient received an ultrasound-guided interfascial block of the trapezius muscle. No studies to date have reported the effectiveness of such blocks in patients with $\mathrm{CEH}$ and exhibiting active TrPs in the trapezius muscle.

\section{Case Reports}

Case 1 - A female patient in her 70s presented with a complaint of headache of 4 years duration. Her headache was on the left side, could be provoked by cervical movements, and was accompany by limitations in neck movement and ipsilateral non-radicular pain in her left shoulder. The pain duration was generally between $5 \mathrm{~h}$ and 3 days. Her Numerical Rating Scale (NRS) score for pain intensity was 10 . We determined a TrP in her left upper trapezius muscle. Brain magnetic resonance imaging did not reveal secondary causes of the headache and she did not have neurological impairment. Because the patient was not treated with medication or physical therapy, we performed an ultrasound-guided interfascial block of the trapezius muscle.

The procedure was performed in the operating room with the patient positioned in the prone position. Standard monitoring (electrocardiography, non-invasive blood pressure, and peripheric oxygen saturation) was utilized and an IV catheter put in place. The skin area was aseptically draped with sterile towels and anesthetized with $2 \%$ prilocaine. We used a Logiq P5 ultrasound (Avante Health Solutions, Concord, North Carolina, United States) with the linear probe at 6-13 MHz. The probe was placed longitudinally between the acromion and the $\mathrm{C} 7$ spinous process. The trapezius and levator scapula muscles and their fasciae were visualized. The injection was made between the trapezius muscle and the levator scapula muscle fascia. A disposable 22 gauge, $10 \mathrm{~cm}$ quincke tip spinal needle was inserted in the interfascial plane. The needle was connected through a $25 \mathrm{~cm}$ flex- ible extension tube to a syringe with physiological saline solution (PS) and 2-3 mL of PS was injected. The needle was repositioned until anechoic diffusion was observed. When the correct space was confirmed, the syringe was changed and $10 \mathrm{~mL}$ of $0.125 \%$ bupivacaine was injected between the muscle fasciae. Following treatment, the cannula was removed and a sterile adhesive plaster was placed over the puncture site. Her NRS score at 30 min after the procedure was 2 . There were no complications during the procedure, and the patient had no complications and was pain free during the 2-month follow-up period.

Case 2 - A female patient in her 50s presented with a complaint of headache of 1 year duration. Her headache was on the left side, could be provoked by cervical movements, and was accompanied by limitations in neck movement. Her pain duration was generally between $5 \mathrm{~h}$ and 3 days. Her NRS score for pain intensity was 8 . We determined a TrP in her left upper trapezius muscle. Brain magnetic resonance imaging had revealed no secondary causes of the headache and she had no neurological impairments. Because the patient was not treated with medication and physical therapy, ultrasound-guided interfascial block of the trapezius muscle was planned.

We performed the same procedures as described above to the patient's left side. Her NRS score at 30 min after procedure was 3 . There were no complications during the procedure, and the patient had no complications and was pain free during the 2-week follow-up period. Both patients consented to the publication of the report.

\section{Discussion}

Sjaastad et al. ${ }^{[17]}$ have shown that the symptoms of CEH can be induced by firm manual pressure on "certain tender spots in the neck." Zito et al. ${ }^{[18]}$ showed that incidence of tightness in the upper trapezius, levator scapulae, scalenes, and the suboccipital extensors was statistically higher in a CEH group than in migraine and control groups. Fernandez-de-las-Penas et al. ${ }^{[19]}$ suggested that pain from TrPs in the posterior cervical, head, and shoulder muscles typically refers to the temporal and frontal areas of the head. Olivier et al. ${ }^{[10]}$ investigated whether TrP sensitivity in the upper trape- 
zius, sternocleidomastoid, temporalis, or posterior cervical muscles is a differentiating factor between cervicogenic and non-CEHs. Their study found that myofascial TrPs in the upper trapezius muscle are more sensitive in patients with $\mathrm{CEH}$ than in those with non-CEH.

Inactivation of TrPs to restore normal muscle length and function is the corner stone of pain relief. Injection techniques are one of the main treatment methods for painful TrPs and include methods such as local anesthetic injections, dry needling, and interfascial plane blocks. ${ }^{[20]}$ Fascia consists of undifferential mesenchymal tissue and forms a thin layer between muscles and adjacent organs. This layering creates interfascial space, resulting in a separate compartment between muscles, allowing independent movement of muscles and fibers, and providing circulation support, and protection. ${ }^{[21]}$ This space is also useful for the administration of analgesic agents. Park et al. ${ }^{[22]}$ found that tone and stiffness of the suboccipital muscles and upper trapezius muscle were increased in patients with $\mathrm{CEH}$ compared to healthy subjects. ${ }^{[22]}$ Blocking of nerve fibers by interfascial injection decreases the sensitivity and relax the muscles and provides pain relief to patients with TrPs.

Various interventional approaches for $\mathrm{CEH}$ such as local injection, nervus occipitalis major and minor block, cervical epidural steroid injection, radiofrequency treatment, and dry needling have been reported in the literature. ${ }^{[23-27]}$ Ischemic compression may also reduce pain in patients with $\mathrm{CEH}$ originating from TrPs in the sternocleidomastoid muscle. ${ }^{[28]}$ Recently, interfascial injections have been used to pain reliever TrPs pain. ${ }^{[14,16]}$ However, there are no reports in the literature regarding interfascial blocks specifically for $\mathrm{CEH}$. Therefore, our use of an ultrasound-guided interfascial block of the trapezius muscle for relief in patients with CEH may contribute to the literature.

The use of ultrasound to assist in interventional techniques has become common. Imaging techniques have provided both effective technique and increased complications. ${ }^{[29]}$ Ultrasound-guided hydrodissection techniques can identify the shape of interfascial spaces, for example, fusiform, and the oc- currence of anechoic diffusion; we used hydrodissection to visualize the interfascial needle placement. Using cadavers, Domingo et al. ${ }^{[14]}$ confirmed diffusion of saline solution in the interfascial space during an ultrasound-guided interfascial block of the trapezius muscle. They also showed a rich innervation network penetrating to fascia in interfascial space, clarifying the effect of local anesthetic on myogenic pain. In an accompanying, clinical study, the authors also found the interfascial block in the trapezius muscle to be as effective as in abdominal muscles. Similar to our results, Domingo et al. ${ }^{[14]}$ study reported pre-injection mean visual analog scale (VAS) of 6.4 (at rest) and 7.6 (in motion), and post-injection mean VAS of 1 (at rest) and 1.6 (in motion).

\section{Conclusion}

In the present multiple case report, we present our use of ultrasound-guided interfascial blocks of the trapezius muscle in two patients with $\mathrm{CEH}$. We suggest that this treatment may produce positive effects for patients with CEH caused by TrPs. Further followup studies are needed to reveal long-term outcomes of interfascial blocks of the trapezius muscle and other TrPs for relief of CEH.

\section{References}

1. Chaibi A, Russell MB. Manual therapies for cervicogenic headache: A systematic review. J Headache Pain 2012;13(5):351-9. [CrosRef]

2. Bogduk N. Govind J. Cervicogenic headache: an assessment of the evidence on clinical diagnosis, invasive tests, and treatment. Lancet Neurol 2009;8(10):959-68. [CrosRef]

3. Suijlekom H, Zundert JV, Narouze S, Kleef M, Mekhail N. Cervicogenic headache. Philadelphia: Wiley-Blackwell; 2012. p. 4-44. [CrosRef]

4. Biondi DM. Cervicogenic headache: A review of diagnostic and treatment strategies. J Am Osteopath Assoc 2005;105(4):16S-22.

5. Sjaastad O, Fredriksen TA. Cervicogenic headache: Criteria, classification and epidemiology. Clin Exp Rheumatol 2000;18(2):S3-6.

6. Fishbain DA, Lewis J, Cole B, Cutler RB, Rosomoff RS, Rosomoff HL. Do the proposed cervicogenic headache diagnostic criteria demonstrate specificity in terms of separating cervicogenic headache from migraine? Curr Pain Headache Rep 2003;7(5):387-94. [CrosRef]

7. Martelletti $P$, van Suijlekom $H$. Cervicogenic headache: Practical approaches to therapy. CNS Drugs 2004;18:793805. [CrosRef]

8. Sjaastad O, Fredriksen TA, Pfaffenrath V. Cervicogenic headache: Diagnostic criteria. The cervicogenic headache 
International study group. Headache 1998;38(6):442-5.

9. Sjaastad O, Bakketeig LS. Prevalence of cervicogenic headache: Vaga study of headache epidemiology. Acta Neurol Scand 2008;117(3):173-80. [CrosRef]

10. Olivier B, Pramod A, Maleka D. Trigger point sensitivity is a differentiating factor between cervicogenic and non-cervicogenic headaches: a cross-sectional, descriptive study. Physiother Can 2018;70(4):323-9. [CrosRef]

11. Fernandez-de-las-Penas $C$, Cuadrado ML, Arendt-Nielsen L, Simona DG, Pareja JA. Myofascial trigger points and sensitization: an updated pain model for tension-type headache. Cephalalgia 2007;27(5):383-93. [CrosRef]

12. Chou LW, Kao MJ, Lin JG. Probable mechanisms of needling therapies for myofascial pain control. Evid Based Complement Alternat Med 2012;2012:705327. [CrosRef]

13. Simons DG. New views of myofascial trigger points: etiology and diagnosis. Arch Phys Med Rehabil 2008;89(1):1579. [CrosRef]

14. Domingo T, Blasi J, Casals M, Mayoral V, Ortiz-Sagrista JC, Miguel-Perez M. Is interfascial block with ultrasound-guided puncture useful in treatment of myofascial pain of the trapezius muscle? Clin J Pain 2011;27(4):297-303. [CrosRef]

15. McDonnell JG, O'Donnell B, Curley G, Heffernan A, Power C, Laffey JG. The analgesic efficacy of transversus abdominis plane block after abdominal surgery: a prospective randomized controlled trial. Anesth Analg 2007;104(1):193-7.

16. Park SM, Cho YW, Ahn SH, Lee DG, Cho HK, Kim SY. Comparison of the effects of ultrasound-guided interfascial pulsed radiofrequency and ultrasound-guided interfascial injection on myofascial pain syndrome of the gastrocnemius. Ann Rehabil Med 2016;40(5):885-92. [CrosRef]

17. Sjaastad O, Fredriksen TA, Pfaffenrath V. Cervicogenic headache: diagnostic criteria. Headache 1990;30(11):7256. [CrosRef]

18. Zito G, Jull G, Story I. Clinical tests of musculoskeletal dysfunction in the diagnosis of cervicogenic headache. Man Ther 2006;11(2):118-29. [CrosRef]
19. Fernandez-de-las-Penas C, Simons D, Cuadrado ML, Pareja J. The role of myofascial trigger points in musculoskeletal pain syndromes of the head and neck. Curr Pain Headache Rep 2007;1 1(5):365-72. [CrosRef]

20. Alvarez DJ, Rockwell PG. Trigger points: diagnosis and management. Am Fam Physician 2002;65(4):653-60.

21. Benjamin M. The fascia of the limbs and back: A review. J Anat 2009;214(1):1-18. [CrosRef]

22. Park SK, Yang DJ, Kim JH, Heo JW, Uhm YH, Yoon JH. Analysis of mechanical properties of cervical muscles in patients with cervicogenic headache. J Phys Ther Sci 2017;29(2):332-5. [CrosRef]

23. Sedighi A, Nakhostin Ansari N, Naghdi S. Comparison of acute effects of superficial and deep dry needling into trigger points of suboccipital and upper trapezius muscles in patients with cervicogenic headache. J Bodyw Mov Ther 2017;21(4):810-4. [CrosRef]

24. Fredriksen TA. Cervicogenic headache: İnvasive procedures. Cephalalgia 2008;28(1):39-40. [CrosRef]

25. Wang E, Wang D. Treatment of cervicogenic headache with cervical epidural steroid injection. Curr Pain Headache Rep 2014;18(9):442. [CrosRef]

26. Naja ZM, El-Rajab M, Al-Tannir MA, Ziade FM, Tawfik OM. Occipital nerve blockade for cervicogenic headache: $A$ double-blind randomized controlled clinical trial. Pain Pract 2006;6(2):89-95. [CrosRef]

27. Ng A, Wang D. Cervical facet injections in the management of cervicogenic headaches. Curr Pain Headache Rep 2015;19(5):11. [CrosRef]

28. Jafari M, Bahrpeyma F, Togha M. Effect of ischemic compression for cervicogenic headache and elastic behavior of active trigger point in the sternocleidomastoid muscle using ultrasound imaging. J Bodyw Mov Ther 2017;21(4):933-9.

29. Kumbhare D, Singh D, Rathbone HA, Gunn M, GrosmanRimon L, Vadasz B, et al. Ultrasound-guided interventional procedures: Myofascial trigger points with structured literature review. Reg Anesth Pain Med 2017;42(3):407-12. 